\title{
SEISMIC PERFORMANCE ANALYSIS OF A RESILIENT PRESTRESSED STEEL FRAME WITH INTERMEDIATE COLUMN CONTAINING FRICTION DAMPERS
}

\author{
Yanxia Zhang $^{1 *}$, Anran Liu ${ }^{2}$, Ailin Zhang ${ }^{3}$ and Xuechun Liu ${ }^{4}$ \\ ${ }^{1}$ Professor, Beijing Advanced Innovation Center for Future Urban Design , \\ Beijing University of Civil Engineering and Architecture, Beijing 100044, China \\ ${ }^{2}$ Postgraduate, School of Civil and Transportation Engineering, \\ Beijing University of Civil Engineering and Architecture, Beijing 100044, China \\ ${ }^{3}$ Professor, School of Civil and Transportation Engineering,Beijing University of Civil Engineering and Architecture, \\ Beijing 100044,Beijing Engineering Research Center of High-Rise and \\ Large-Span Prestressed Steel Structure, Beijing University of Technology, Beijing 100124, China \\ ${ }^{4}$ Associate Professor, Beijing Engineering Research Center of High-Rise and \\ Large-Span Prestressed Steel Structure, Beijing University of Technology, Beijing 100124, China \\ *(Corresponding author: E-mail: zhangyanxia@bucea.edu.cn)
}

Received: 18 August 2015; Revised: 13 June 2016; Accepted: 3 August 2016

\begin{abstract}
A resilient prestressed steel frame system with intermediate columns containing friction dampers (ICRPSF) has been proposed for the use in a large span, seismically active regions and a high-value building. Seismic performance analysis of overall structure of a resilient prestressed steel frame with intermediate column friction damper are analyzed, compared with the resilient performance of a resilient prestressed steel frame (RPSF) with beam web friction damper. The results show that an ICRPSF effectively controls the story drift, dissipates more energy through the intermediate column friction damper (ICFD) and curbs the plastic development of the component. This system has a small post-seismic residual story drift and its structure demonstrates excellent self-centering capability.
\end{abstract}

Keywords: Intermediate column, friction dampers, resilient prestressed steel frame, seismic performance analysis, energy dissipation

DOI: $10.18057 /$ IJASC.2017.13.3.3

\section{INTRODUCTION}

Resilient prestressed steel frame structures (hereafter known as RPSF) can reduce structural damage, reduce or eliminate residual deformations, and is easy to repair after a strong earthquake. Therefore, it has caused researchers' widespread attention, and has been extensively studied. The connection for RPSF used post-tensioned steel strands being with bolted top and seat angles was proposed by Ricles et al. [1]. Garlock et al. [2,3] investigated the connection behavior through experiments and the design procedures of post-tensioned frame systems has been put forward. Christopoulos et al. [4] invented a post-tensioned energy dissipating connection with post-tensioned high-strength bars, and investigated connection performance analytically and experimentally. Rojas et al. [5] developed a connection which adopted friction devices on the top and bottom flanges of the beam and post-tensioned high strength strands running parallel to the beam. In order to avoid interference with the floor slab, Wolski et al. [6] developed another the flange friction device which only attached to the bottom flange of the beam. Tsai et al [7] presented experimental and analytical studies on the connection with bolted web friction devices (WFD). Lin et al. [8,9] carried out an experimental study of self-centering moment-resisting steel frame (SC-MRF) with WFD connections under the action of design basis earthquake and maximum considered earthquake ground motions. Zhang et al. performed the experiments, finite element analysis and theory analysis of the self-centering connections with the WFDs [10], as well as investigated the dynamic behavior through the time-history analysis of integral SC-MRFs with finite element software 
ABAQUS [11]. Thereafter, Zhang et al. [12] proposed a prefabricated post-tensioned self-centering beam-column connection using a bolted web friction device, conducted the low-cycle loading experiments, carried out relevant theoretical analyses and investigated the seismic performance of the connection. Therefore, the pseudo-dynamic test towards the resilient prefabricated prestressed steel frame has been performed by Zhang et al.[13].In the research of the large-span resilient steel frame, the resilient prestressed frame with intermediate columns containing friction damper (hereafter known as ICRPSF) has been propose by Zhang et al., which both the static pushover test and the finite element analysis toward the first 2 floor plane frame have been carried out to investigate the working behavior of intermediate columns and the hysteretic performance of ICRPSF [14]. In this thesis, the finite element model of an eight-floor ICRPSF structure is built up, and the comparative analysis with the RPSF used beam web friction dampers is performed in the consideration of the seismic performance. The properties of the ICRPSF, such as the base shear, the story drift, the residual story drift, the energy dissipation capability and the post-seismic structure recovery performance, are investigated.

\section{SYSTEM STRUCTURE OF THE ICRPSF}

A plane steel frame system is used to illustrate the detailed structure of the system, as shown in Figure 1 and Figure 2. ICRPSF is composed of RPSF with web friction damper and the intermediate column containing friction damper (ICFD). ICFD can be divided into three parts: the upper column, the lower column, and the damper [15]. The upper and lower columns are welded to the floor beams or column base, and the haunches are set up at the connecting ends to increase the strength of the joints. The upper and lower columns are connected through the damper. The damper includes a T-shaped steel plate that used to connect with the upper column and two L-shaped steel plates that used to connect the lower column. In addition, there are brass plates sandwiched between the L-shaped and T-shaped plates through high-strength bolts. An elongated hole in the T-shaped plate allows the ends of the upper and lower columns to move relatively under an earthquake. And therefore, the high-strength bolts can dissipate energy by friction. To enable easy replacement of the damper following an earthquake, the T-shaped and L-shaped steel plates are connected to the upper and lower columns with high-strength bolts, respectively.

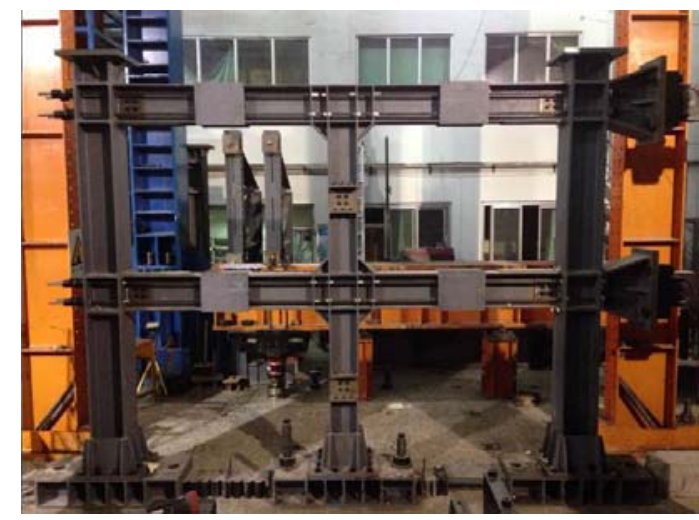

Figure 1. Photograph of ICRPSF

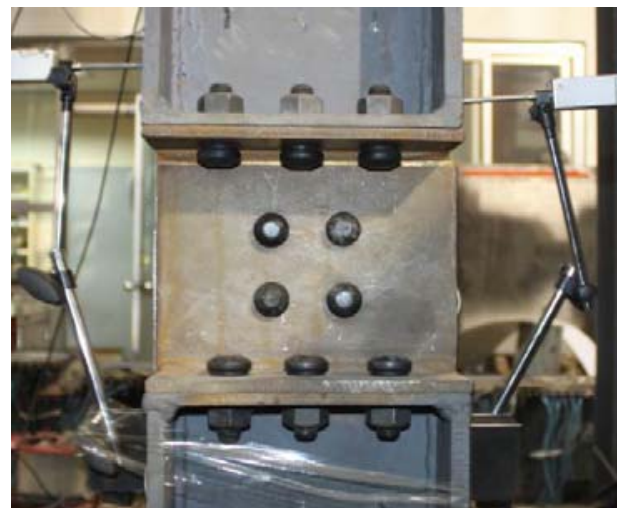

Figure 2. Details of the ICFD

\section{IMPLEMENTATION OF THE ICFD HYSTERESIS PERFORMANCE IN THE STRUCTURAL ANALYSIS}

A group of friction-sliding tests are designed to analyze the friction damper under repeated loads, as shown in Figure 3. The force-slippage hysteresis curve of the friction damper is obtained, which shape is approaching an ideal rectangle, as shown in Figure 4. 
In the overall structural model of the ICRPSF, a connector is defined to simulate the force- slippage relation of the intermediate column, which the rectangular hysteresis curve of the ICFD is implemented. The connector spring unit is created in the interaction module of the software ABAQUS, and the translator connector is used to constrain all rotational degrees of freedom (DOFs), as shown in Figure 5. The translational DOF in the U1 direction is defined as the direction that the slip of the friction damper occurs. Simultaneously, translational DOFs in the other 2 directions are constrained, and the input is the friction $F_{f}$. The connector slippage and the connector force in the corresponding direction are monitored to obtain the force- slippage hysteresis curve of the friction damper, as shown in Figure 6. The data in Figure 4 and Figure 6 show that the force-slippage hysteresis curve obtained from the finite element analysis (FEA) is consistent with the curve obtained from the test.

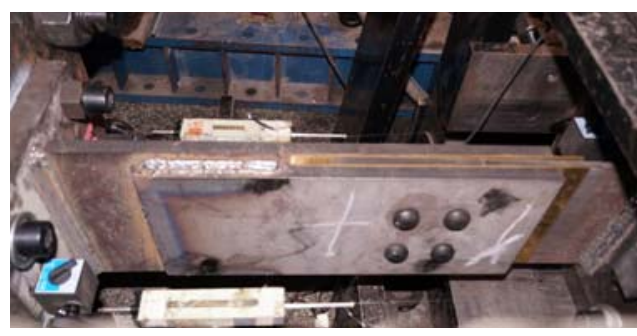

Figure 3. Friction-sliding Test
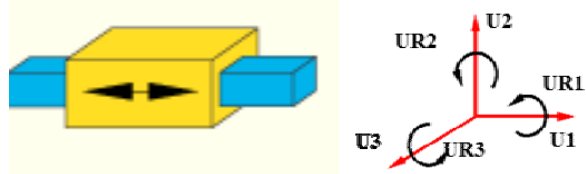

Figure 5. Schematic of Translator Connector

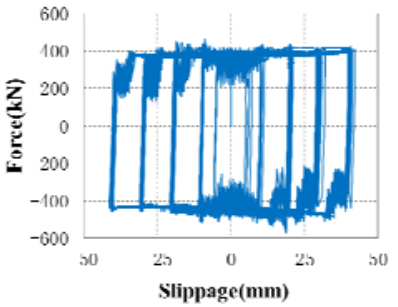

Figure 4. Hysteresis Curve of Friction Damper Test

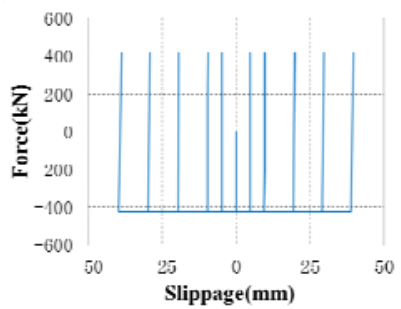

Figure 6. Force- Slippage Hysteresis Curve from FEA

\section{SAMPLE STRUCTURE AND MODAL ANALYSIS RESULTS OF 2 TYPES OF STRUCTURES}

\subsection{Sample Structure}

Sample frame structure has 8 floors. The height of the first floor is $3.9 \mathrm{~m}$, and the height is $3.6 \mathrm{~m}$ for 2-8 floors. There are 3 spans widthwise and 5 spans lengthwise, and each span measures $12 \mathrm{~m}$. The plane diagram of the structure is shown in Figure 7. The red sections shown Figure7 used ICRPSF for floors 1-6, and the RPSF for floors 7-8. Meanwhile, the frame adopted the hinge system except the red sections. Three-dimension finite element model of ICRPSF is shown in Figure 8. The fortification strength was 8 degree. The floor constant load was $7.0 \mathrm{kN} / \mathrm{m}^{2}$, the floor variable load was $2.0 \mathrm{kN} / \mathrm{m}^{2}$, and the roof variable load was $0.5 \mathrm{kN} / \mathrm{m}^{2}$. The main parameters of the structure are defined as follows. For the dimensions of the frame, the box column is $650 \mathrm{~mm} \times 650 \mathrm{~mm} \times 32 \mathrm{~mm} \times 32 \mathrm{~mm}$, the H-shaped rigid beam is $750 \mathrm{~mm} \times 350 \mathrm{~mm} \times 24 \mathrm{~mm} \times 30 \mathrm{~mm}$, the box hinge column is $500 \mathrm{~mm} \times 500 \mathrm{~mm} \times 24 \mathrm{~mm} \times 24 \mathrm{~mm}$, the H-shaped hinge beam is $650 \mathrm{~mm} \times 300 \mathrm{~mm} \times 12 \mathrm{~mm} \times 20 \mathrm{~mm}$, and the H-shaped intermediate column is $500 \mathrm{~mm} \times 350 \mathrm{~mm} \times 14 \mathrm{~mm} \times 20 \mathrm{~mm}$, as well as six 10.9 -degree grade M20 bolts are used in the ICFD. The prestressed beam-column connection uses web friction energy dissipation device. Twelve 10.9-degree M24 high-strength bolts are used in an even distribution, with 4 rows and 3 columns. Each beam-column connection adopted twelve 1×19 low relaxation high strength steel strands with 
the nominal tensile strength grade valued $1860 \mathrm{MPa}$. The initial prestressed value of each steel strand is set to $0.4 T_{\mathrm{u}}$. RPSF model is established after removing all intermediate columns from the model introduced above, which is used to analyze the seismic performance of ICRPSF in comparison.

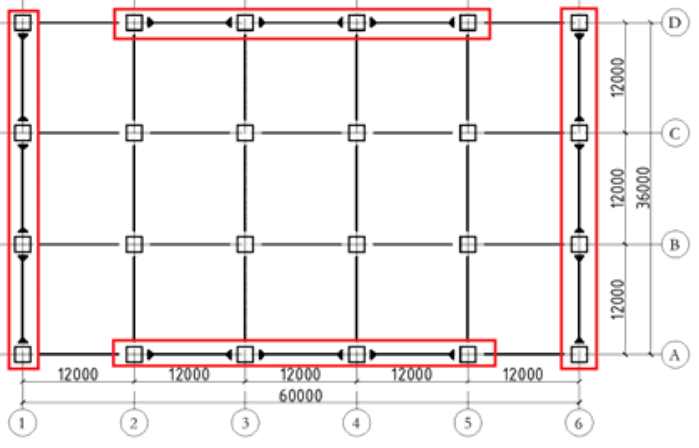

Figure 7. Plane Schematic of Structure

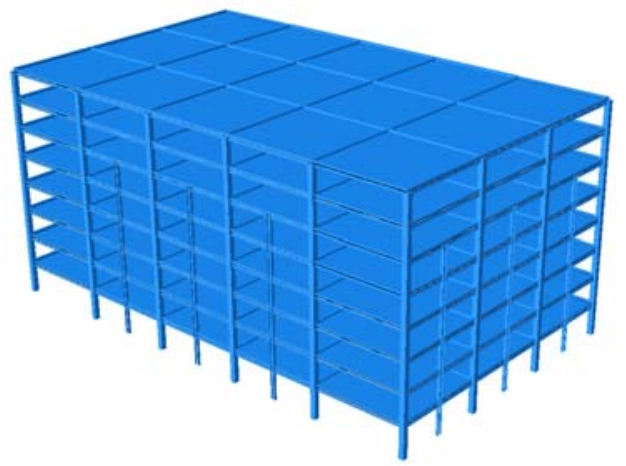

Figure 8. Three-dimensional FEA Model of ICRPSF

\subsection{Modal Analysis Results of 2 Types of the Structure}

Using the ABAQUS software, a linear perturbation analysis is set up to perform the modal analysis and obtain the natural frequencies of the structure. The eigenvalue solver uses the Lanczos method to calculate the first 18 frequencies and periods for both types of frames (ICRPSF and RPSF). Each vibration mode of 2 types of the frame is investigated and compared. The comparison of the first three vibration modes shows that the first three vibration modes of ICRPSF are consistent with those of RPSF. Each natural period calculated from the frequency is shown in Table 1. The data show that, compared with the RPSF, the period of the ICRPSF is significantly reduced, i.e., the reduction amplitudes of first three natural periods can reach $26 \%$ at the least. The result indicates that, ICFD, which is used in the design of the ICRPSF, provides higher lateral rigidity and torsional rigidity than those of RPSF significantly. Therefore, the utilization of ICFD in the ICRPSF contributes significantly to the overall rigidity of the structure.

Table 1. Comparison of the First Three Natural Vibration Periods of Two Frames (s)

\begin{tabular}{cccc}
\hline Frame & 1 & 2 & 3 \\
\hline RPSF & 2.697 & 2.665 & 1.644 \\
ICRPSF & 1.993 & 1.915 & 1.203 \\
Deviation ratio & $26.08 \%$ & $28.16 \%$ & $26.81 \%$ \\
\hline
\end{tabular}

\section{GROUND MOTION SELECTION FOR THE TIME HISTORY ANALYSIS}

The 3-dimension ground motion data of 22 far-field earthquakes recommended in report ATC-63 [16] and the EL-Centro, the Taft wave and the Wenchuan earthquake's 4 waves are used to perform the time history analysis. The natural period of the ICRPSF is around 2 seconds. The percentages of the difference (delta) of earthquake influence coefficient between every ground motion response spectrum and the standard spectrum at the natural period of 2 seconds is calculated. As the space is limited, 8 selected typical ground motions are selected according to the calculated difference of influence coefficients. The typical acceleration Fourier spectrum transformed by software SeismoSignal is shown in Figure 9. Differences of the earthquake influence coefficients, in descending order, are GM1 to GM8, as shown in Table 2. 
During the finite element calculation, the bi-directional horizontal component of each ground motion is used, and its amplitude is modulated to 8-degree frequent, design, rare, and 8.5-degree rare earthquake conditions according to Chinese Code for Seismic Design of Buildings [17], i.e., the peak ground acceleration (PGA) are $0.07 \mathrm{~g}, 0.2 \mathrm{~g}, 0.4 \mathrm{~g}$ and $0.51 \mathrm{~g}$, respectively. In the model, the primary direction is $\mathrm{Z}$, the secondary direction is $\mathrm{X}$ which the amplitude is scaled to 0.85 .

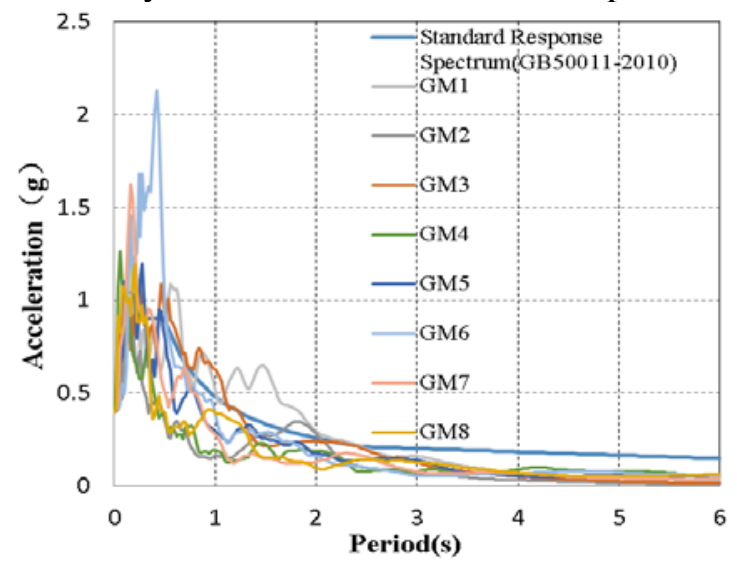

Figure 9. Acceleration Response Spectrum

Table 2. 8 Ground Motions for Time-history Analysis

\begin{tabular}{ccccc}
\hline $\begin{array}{c}\text { Ground } \\
\text { motions }\end{array}$ & $\begin{array}{c}\text { Magnitu } \\
\text { de }\end{array}$ & Year & Description & $\begin{array}{c}\text { Influence } \\
\text { coefficient delta }\end{array}$ \\
\hline GM1 & 6.9 & 1995 & Kobe,Japan & $13.11 \%$ \\
GM2 & 6.7 & 1994 & Northridge & $8.66 \%$ \\
GM3 & 7 & 1940 & Imperial Valley & $-7.04 \%$ \\
GM4 & 6.5 & 1979 & Imperial Valley & $-27.12 \%$ \\
GM5 & 7.1 & 1999 & Hector Mine & $-32.53 \%$ \\
GM6 & 8 & 2008 & Shifang Bajiao & $-55.32 \%$ \\
GM7 & 7.4 & 1990 & Manjil,Iran & $-48.99 \%$ \\
GM8 & 7.1 & 1999 & Duzce,Turkey & $-62.43 \%$ \\
\hline
\end{tabular}

\section{TIME HISTORY DYNAMIC ANALYSIS RESULTS}

The dynamic responses of the ICRPSF and RPSF under 8-degree frequent, design, rare earthquakes and 8.5-degree rare earthquake are analyzed in detail to investigate the seismic performance of the ICRPSF. Because the two frames have no connection gap opening and ICFD slippage under the 8-degree frequent earthquakes, and due to the space is limited, only the analytical results under 8-degree design (0.2g) and 8.5-degree rare earthquake (0.51g) are listed here.

\subsection{The 8-degree Design Ground Motion (PGA=0.2g)}

(1) Slippages of the friction damper and connection gap opening

Table 3 shows the maximum slippages of the friction damper of ICRPSF in both directions under 8-degree design earthquake conditions. The maximum slippage response of the ICFD is higher under the ground motions with larger influence coefficients. The maximum slippage is $20.2 \mathrm{~mm}$ in $\mathrm{X}$-direction under the GM3 ground motion. Table 4 shows the maximum connection gap opening under 8-degree design earthquake, indicating that the difference of connection gap opening is not much. 
Table 3. Maximum ICFD Slippage under 8-degree Design Earthquake（mm）

\begin{tabular}{cccccccccc}
\hline \multirow{2}{*}{ Ground motions } & \multirow{2}{*}{ GM 1 } & \multirow{2}{*}{ GM 2 } & \multirow{2}{*}{ GM 3 } & GM & GM & GM & GM & GM \\
& & & & 4 & 5 & 6 & 7 & 8 \\
\hline \multirow{2}{*}{ ICRPSF } & Z direction & 14.9 & 0.5 & 15.4 & 0 & 3.4 & 2.1 & 3.6 & 0 \\
& X direction & 10.9 & 7.8 & 20.2 & 0.1 & 0.1 & 0.1 & 0.1 & 0.1 \\
\hline
\end{tabular}

Table 4. Maximum Connection Gap Opening under 8-degree Design Earthquake（mm）

\begin{tabular}{cccccccccc}
\hline \multicolumn{2}{c}{ Ground motions } & GM & GM & GM & GM & GM & GM & GM & \multirow{2}{*}{ GM 8 } \\
& & 1 & 2 & 3 & 4 & 5 & 6 & 7 & \\
\hline \multirow{2}{*}{ ICRPSF } & Z direction & 1.925 & 0.365 & 1.624 & 0.168 & 0.563 & 0.42 & 0.577 & 0.266 \\
& X direction & 0.999 & 1.398 & 1.753 & 0.24 & 0.176 & 0.109 & 0.116 & 0.258 \\
\multirow{2}{*}{ RPSF } & Z direction & 1.343 & 0.274 & 1.996 & 0.141 & 1.76 & 0.243 & 1.036 & 0.266 \\
& X direction & 2.821 & 1.217 & 2.981 & 0.197 & 0.11 & 0.151 & 0.263 & 0.198 \\
\hline
\end{tabular}

(2) Comparison of the base shear

Figure 10 shows the base shear time history comparisons of both frames under 3 ground motions of 8-degree design earthquake. Table 5 shows the maximum base shears of the ICRPSF and the RPSF in the primary and secondary directions under 8 typical ground motions of 8-degree design earthquake. The data in Figure 10 and Table 5 show that, in both directions, the base shears of ICRPSF are greater than those of RPSF except under the action of ground motion GM6, and the maximum value of ICRPSF is 134\% higher than that of RPSF. Because ICRPSF has higher lateral rigidity and a shorter structure period, which would result in a corresponding increase of the base shear.

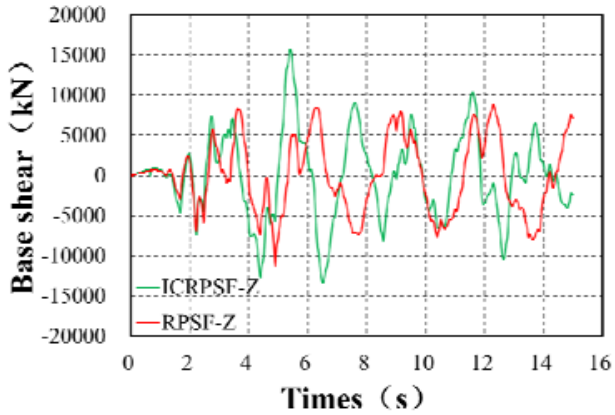

a) GM3 primary direction

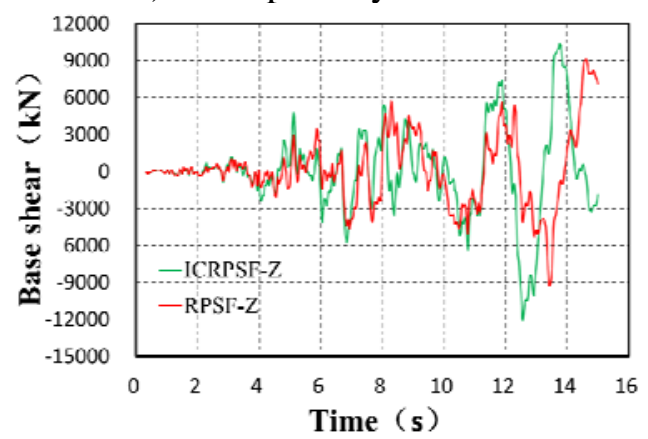

c) GM5 primary direction

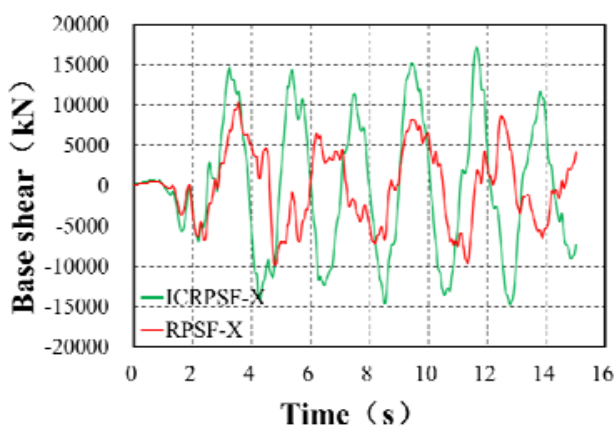

b) GM3 secondary direction

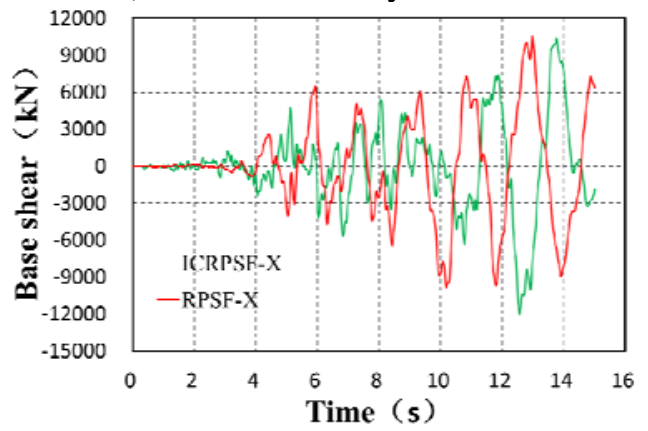

d) GM5 secondary direction 


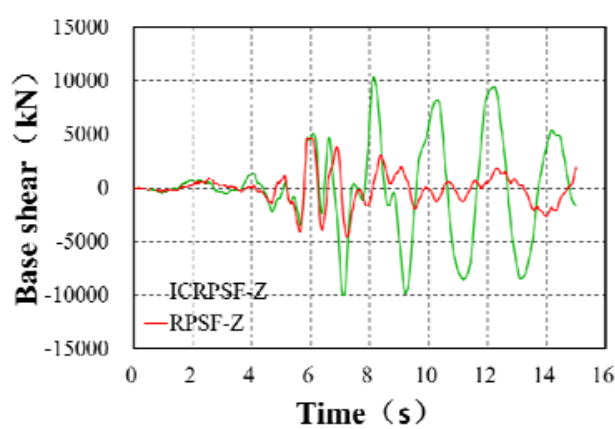

e) GM8 primary direction

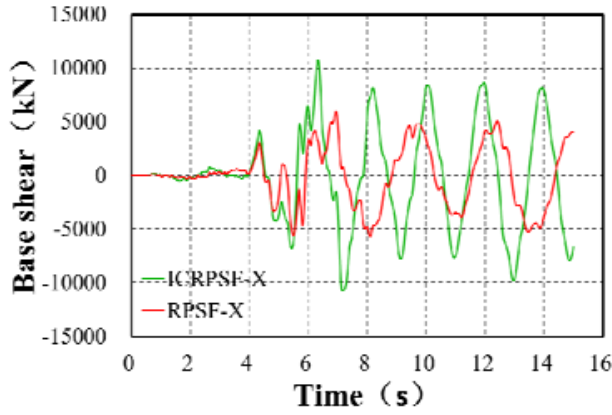

f) GM8 secondary direction

Figure 10. Base-shear time-histories of Two Frames under 8-degree Design Earthquake

Table 5. Maximum Base-shear of Two Frames under 8-degree Design Earthquake

\begin{tabular}{ccccccc}
\hline \multirow{2}{*}{$\begin{array}{c}\text { Ground } \\
\text { motions }\end{array}$} & \multicolumn{2}{c}{ Primary direction $(\mathrm{Z})$} & \multicolumn{3}{c}{ Secondary direction $(\mathrm{X})$} \\
& $\mathrm{kN}$ & $\begin{array}{c}\mathrm{ICRPSF} \\
\mathrm{kN}\end{array}$ & $\begin{array}{c}\text { Delta } \\
\%\end{array}$ & $\begin{array}{c}\text { RPSF } \\
\mathrm{kN}\end{array}$ & $\begin{array}{c}\text { ICRPSF } \\
\mathrm{kN}\end{array}$ & $\begin{array}{c}\text { Delta } \\
\%\end{array}$ \\
\hline GM1 & 9595 & 18303 & 91 & 10940 & 16253 & 49 \\
GM2 & 6426 & 10055 & 56 & 7311 & 15752 & 115 \\
GM3 & 11199 & 15697 & 40 & 10350 & 17190 & 66 \\
GM4 & 5148 & 8242 & 60 & 8572 & 10797 & 26 \\
GM5 & 9285 & 12056 & 30 & 5396 & 10508 & 95 \\
GM6 & 9157 & 5914 & -35 & 11494 & 8700 & -24 \\
GM7 & 8299 & 13034 & 57 & 7772 & 10324 & 33 \\
GM8 & 4649 & 10405 & 124 & 5995 & 10770 & 80 \\
\hline
\end{tabular}

\section{(3) Comparison of the story drift}

Figure. 11 shows the envelope values of the story drifts of ICRPSF and RPSF in the primary and the secondary directions under different 8-degree design ground motions. The maximum story drifts of each floor are shown in Table 6. The data in Figure11 and Table 6 show that the most of maximum story drifts of the ICRPSF are close to or less than those of the RPSF under most of ground motions. The largest values of RPSF and ICRPSF occur in the secondary direction at 3rd floor of the structure under the action of GM3. The maximum story drift of RPSF is $1.244 \%$, and the maximum story drift of ICRPSF is $0.998 \%$.

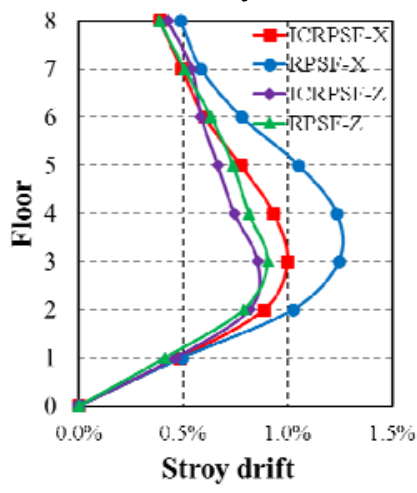

a) GM3

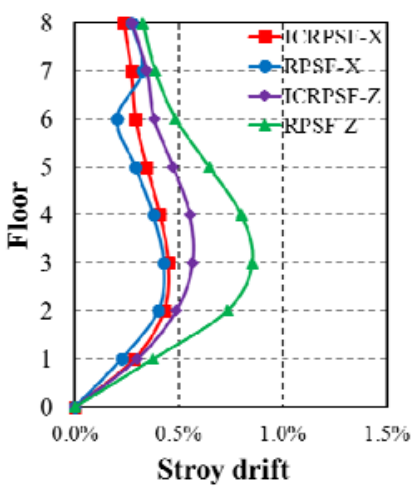

b) $\mathrm{GM} 5$

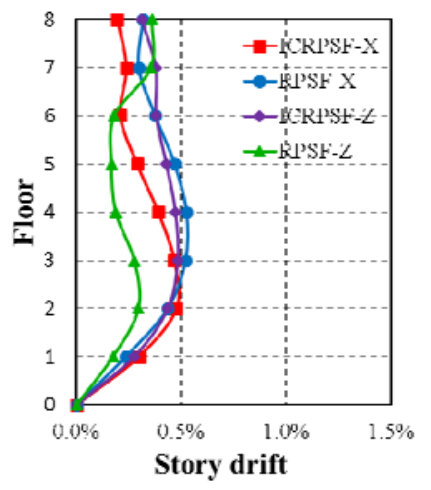

c) $\mathrm{GM} 8$

Figure 11. Comparison of Maximum Story Drifts under 8-degree Design Earthquake 
Table 6. Maximum Story Drifts of Two Frames under 8-degree Design Earthquake（\%rad）

\begin{tabular}{ccccc}
\hline \multirow{2}{*}{ Ground motions } & \multicolumn{2}{c}{$\begin{array}{c}\text { Primary direction (Z) } \\
\text { RPSF }\end{array}$} & ICRPSF & Secondary direction $(X)$ \\
& RPSF & ICRPSF \\
\hline GM1 & 0.757 & 0.871 & 1.117 & 0.654 \\
GM2 & 0.531 & 0.536 & 0.776 & 0.842 \\
GM3 & 0.916 & 0.865 & 1.244 & 1.0 \\
GM4 & 0.368 & 0.382 & 0.491 & 0.469 \\
GM5 & 0.856 & 0.567 & 0.427 & 0.450 \\
GM6 & 0.448 & 0.540 & 0.426 & 0.404 \\
GM7 & 0.707 & 0.566 & 0.607 & 0.369 \\
GM8 & 0.359 & 0.483 & 0.525 & 0.477 \\
\hline
\end{tabular}

(4) Comparison of the residual story drift

Figure 12 shows the comparison of the maximum residual story drifts between ICRPSF and RPSF of each floor under the actions of different 8-degree design ground motions. Large residual story drifts occur primarily in floors with large story drifts. Residual story drifts of ICRPSF are generally greater than those of RPSF. However, the maximum post-seismic residual story drifts of the ICRPSF and RPSF are $0.0646 \%$ and $0.0059 \%$ respectively, which are small enough to be ignored.

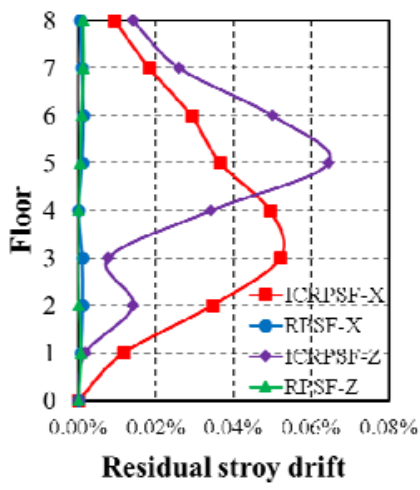

a) GM3

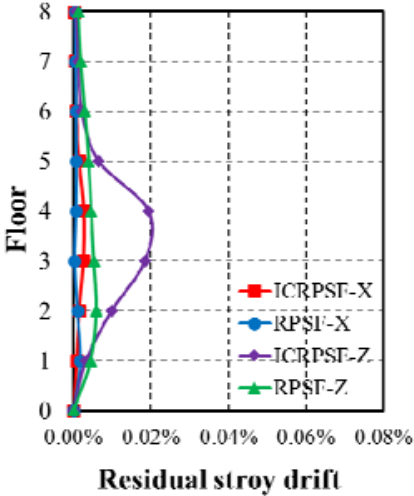

b) GM5

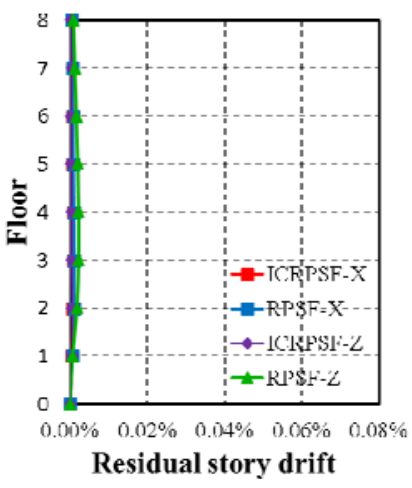

c) GM8

Figure 12. Maximum Residual Story Drift of Two Frames under 8-degree Design Earthquake

Table 7 shows the maximum residual slippage of the friction damper in both directions under the 8-degree design ground motions. The corresponding residual slippage of ICRPSF, the maximum residual slippage of the friction damper is $8.8 \mathrm{~mm}$, is relatively larger after a larger slippage generated by the friction damper. After all, the prestressed strand on the beam provide ICFD limited recovery capability. This will have a few influences on the overall performance of the structure. However, after an earthquake, the high strength bolt can be relaxed to restore the ICFD to its original position.

Table 7. Maximum ICFD Residual Slippage under 8-degree Design Earthquake (mm)

\begin{tabular}{cccccccccc}
\hline Ground motions & GM & GM 2 & GM 3 & GM 4 & GM & GM & GM & GM \\
ICRPSF & $\begin{array}{c}\text { Z } \\
\text { direction } \\
\mathrm{X} \\
\text { direction }\end{array}$ & 7.9 & 0.4 & 8.8 & 0 & 2.9 & 2.1 & 1.4 & 0 \\
\hline
\end{tabular}


(5) Comparison of the energy dissipation

Figure 13 shows the energy dissipation comparison of both frames under the action of 8-degree design ground motions. Each symbol represents the following meanings: EKE-kinetic energy,

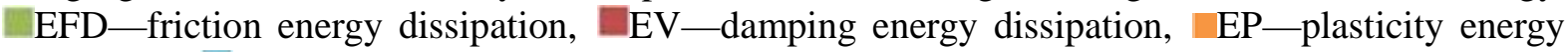
dissipation, EES — elastic strain energy. Table 8 shows the energy dissipation values in detail. Under different ground motions, the total energy absorption of the ICRPSF structure is 35\%, which is greater than that of the RPSF on average, as well as the maximum energy absorption is $60 \%$ higher than that of the RPSF. The kinetic energy and the elastic strain energy of the structure are only part of the energy transformation, which would not dissipate any energy. Under design earthquake conditions, except the friction energy dissipation of the structure is relatively high under a few of intensive ground motions, the friction energy dissipation of the structure is small under most ground motions with lower influence coefficients. Both frames are primarily in the state of damping energy dissipation where non-elastic strain energy dissipation is relatively small, which indicates that the structure is basically in an elastic state at this moment.

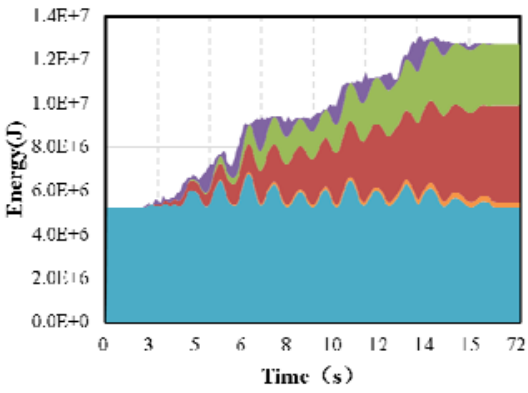

a) GM3 ICRPSF

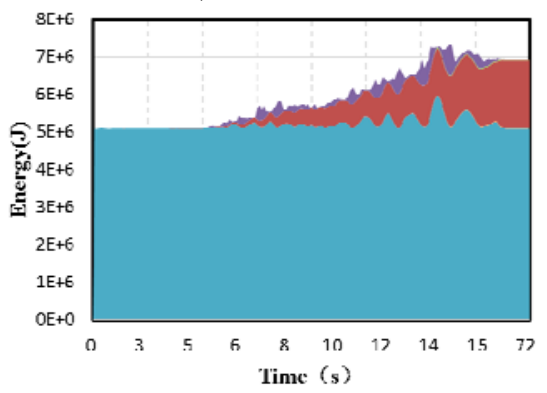

c) GM5 ICRPSF

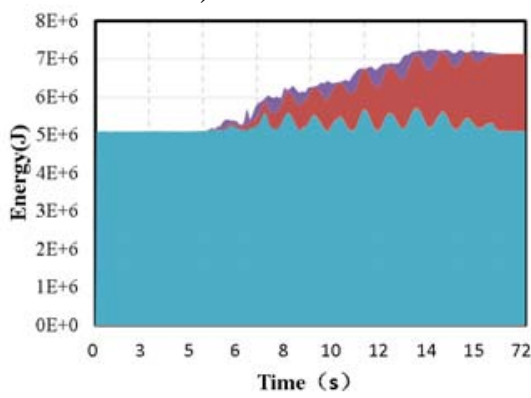

e) GM8 ICRPSF

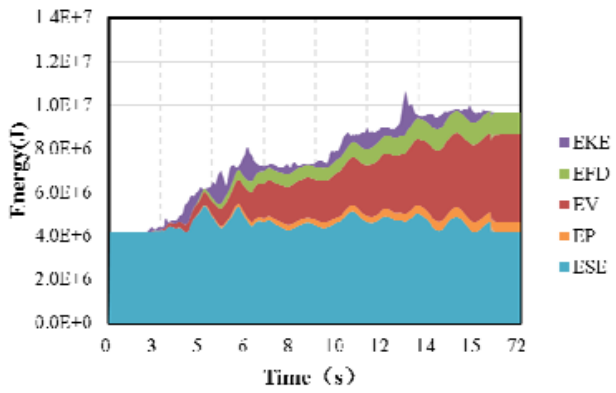

b) GM3 RPSF

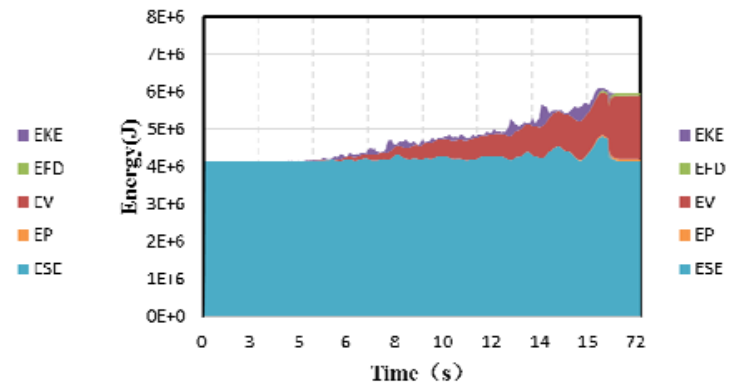

d) GM5 RPSF

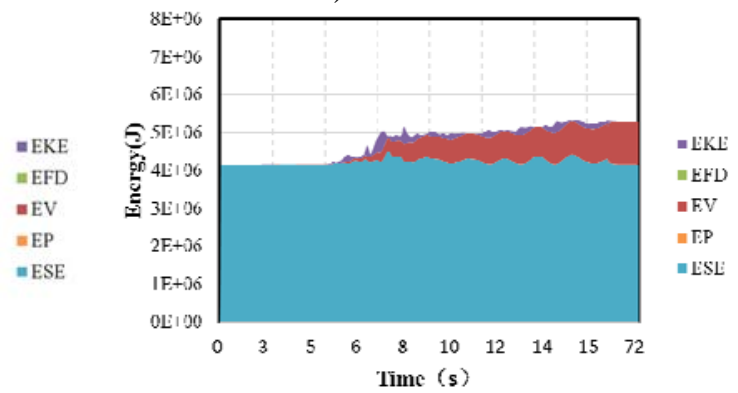

f) GM8 RPSF

Figure 13. Comparison of Energy Dissipation of Two Frames under 8-degree Design Earthquake 
Table 8. Energy Dissipation of Two Frames under 8-degree Design Earthquake

\begin{tabular}{lccccccccc}
\hline \multirow{2}{*}{ Ground motions } & $\begin{array}{c}\text { WK } \\
(\mathrm{J})\end{array}$ & $\begin{array}{c}\text { ESE } \\
(\mathrm{J})\end{array}$ & $\begin{array}{c}\text { EKE } \\
(\mathrm{J})\end{array}$ & $\begin{array}{c}\text { EWK } \\
(\mathrm{J})\end{array}$ & $\begin{array}{c}\text { EP } \\
(\mathrm{J})\end{array}$ & $\begin{array}{c}\text { EP/EWK } \\
(\%)\end{array}$ & $\begin{array}{c}\text { EV/EWK } \\
(\%)\end{array}$ & $\begin{array}{c}\text { EFD/EWK } \\
(\%)\end{array}$ \\
\hline \multirow{2}{*}{ GM1 } & RPSF & 7627810 & 4428420 & 191085 & 3008305 & 158786 & 5.28 & 76.73 & 16.92 \\
& ICRPSF & 9491640 & 5194160 & 125857 & 4171623 & 132659 & 3.18 & 74.56 & 18.82 \\
GM2 & RPSF & 5787700 & 4223510 & 19350 & 1544840 & 22134 & 1.43 & 93.04 & 3.40 \\
& ICRPSF & 9406120 & 5203900 & 215156 & 3987064 & 89918 & 2.26 & 76.76 & 17.33 \\
GM3 & RPSF & 9771210 & 4624010 & 17251 & 5129949 & 446161 & 8.70 & 70.52 & 20.04 \\
& ICRPSF & 12899800 & 5473830 & 40417 & 7385553 & 256293 & 3.47 & 56.16 & 38.27 \\
GM4 & RPSF & 5395010 & 4211120 & 260586 & 923304 & 5322 & 0.58 & 95.55 & 0.02 \\
& ICRPSF & 6927530 & 5491450 & 115991 & 1320089 & 2913 & 0.22 & 88.76 & 0.26 \\
GM5 & RPSF & 6084410 & 4748510 & 62998 & 1272902 & 37949 & 2.98 & 90.40 & 3.72 \\
& ICRPSF & 7089060 & 5274910 & 46209 & 1767941 & 14080 & 0.80 & 89.50 & 1.61 \\
GM6 & RPSF & 6963080 & 4412530 & 44769 & 2505781 & 6002 & 0.24 & 97.99 & 0.00 \\
& ICRPSF & 8994810 & 5251080 & 15423 & 3728307 & 6031 & 0.16 & 95.32 & 0.28 \\
GM7 & RPSF & 6030410 & 4505720 & 140299 & 1384391 & 63450 & 4.58 & 90.85 & 1.65 \\
& ICRPSF & 6868140 & 5271590 & 25392 & 1571158 & 30204 & 1.92 & 86.11 & 2.43 \\
GM8 & RPSF & 5344160 & 4302850 & 70480 & 970830 & 3452 & 0.36 & 96.40 & 0.05 \\
& ICRPSF & 7302010 & 5296490 & 63183 & 1942337 & 14930 & 0.77 & 92.03 & 0.03 \\
\hline
\end{tabular}

*: total energy absorption : WK= ESE+ EKE+ EWK; total energy dissipation: EWK= EP+ EV+EFD

\subsection{The 8.5-degree Rare Earthquake (PGA=0.51g)}

(1) Slippages of the friction damper and connection gap opening

Table 9 shows the maximum slippages of the friction damper of ICRPSF in both directions under 8.5-degree rare earthquake conditions. The ICFD maximum slippage response occurs under the ground motion with the largest influence coefficient. The maximum slippage is $67.3 \mathrm{~mm}$ in $\mathrm{X}$-direction under the action of GM1 ground motion. Therefore, during the seismic design of the structure under the condition of 8.5-degree rare earthquake, the redundancy of the intermediate column damper chute should be taken into account. Table 10 shows the maximum connection gap opening under the action of 8-degree rare earthquake. The data from the Table 10 show that the difference of connection gap opening is not much under most of the ground motions.

Table 9. Maximum ICFD Slippage under 8.5-degree Rare Earthquake（mm）

\begin{tabular}{cccccccccc}
\hline \multicolumn{2}{c}{ Ground motions } & GM 1 & GM 2 & GM 3 & GM 4 & GM 5 & GM 6 & GM 7 & GM 8 \\
\hline \multirow{2}{*}{ ICRPSF } & Z direction & 59.2 & 19.9 & 49.5 & 17.9 & 26.3 & 4.0 & 40.9 & 31.5 \\
& X direction & 67.3 & 48.1 & 67.0 & 26.6 & 23.0 & 3.9 & 23.9 & 4.2 \\
\hline
\end{tabular}

Table 10. Maximum Connection Gap opening under 8.5-degree Rare Earthquake（mm）

\begin{tabular}{cccccccccc}
\hline \multicolumn{2}{c}{ Ground motions } & \multirow{2}{*}{ GM 1 } & \multirow{2}{*}{ GM 2 } & GM 3 & \multirow{2}{*}{ GM 4 } & GM & GM & \multirow{2}{*}{ GM 7 } & \multirow{2}{*}{ GM 8 } \\
\hline \multirow{2}{*}{ ICRPSF } & Z direction & 10.906 & 3.538 & 5.078 & 2.353 & 3.339 & 0.688 & 4.018 & 3.206 \\
& X direction & 14.124 & 4.271 & 6.072 & 2.694 & 2.179 & 0.501 & 2.202 & 2.050 \\
\multirow{2}{*}{ RPSF } & Z direction & 4.608 & 3.559 & 6.179 & 2.466 & 5.166 & 2.864 & 4.813 & 4.028 \\
& X direction & 7.784 & 4.085 & 9.713 & 9.307 & 2.235 & 3.074 & 3.519 & 2.725 \\
\hline
\end{tabular}


(2) Comparison of the base shear

Figure.14 shows comparison towards the base shear time history responses between both frames in both directions under 8.5-degree rare earthquake conditions. The base shear time history responses of both frame structures under different ground motions show that both the trends of responses are in the same under rare earthquake conditions, where the response magnitude of ICRPSF is approximately $10 \%$ higher than that of the RPSF.

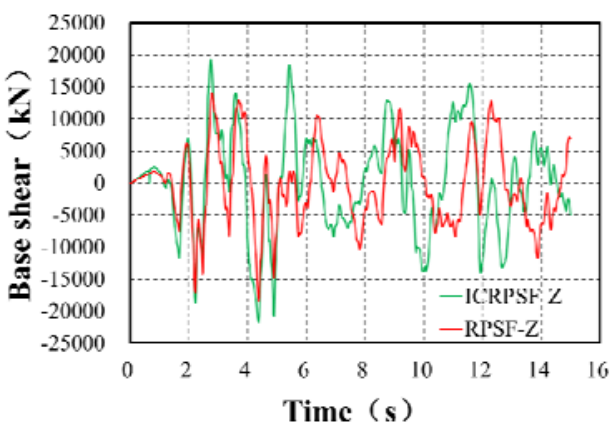

a) GM3 primary direction

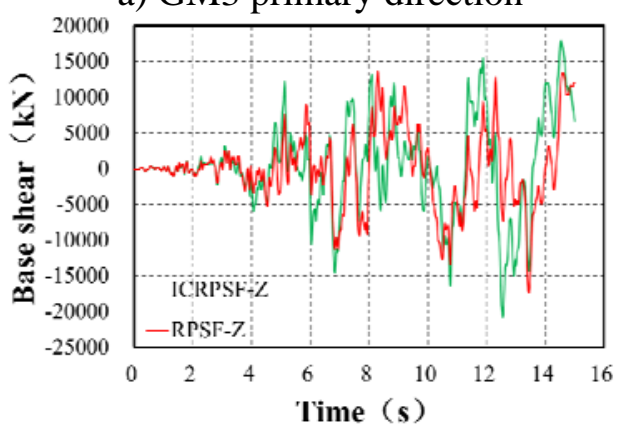

c) GM5 primary direction

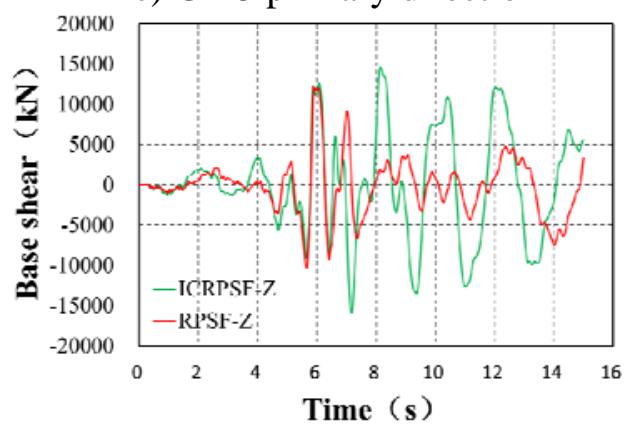

e) GM8 primary direction

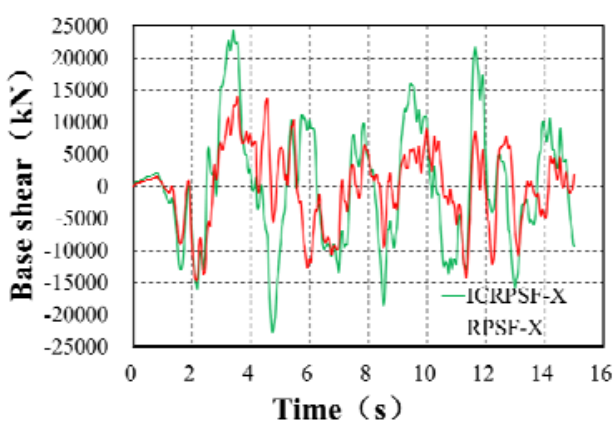

b) GM3 secondary direction

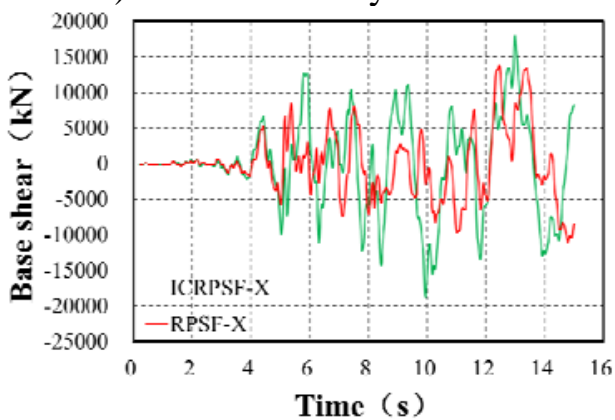

d) GM5 secondary direction

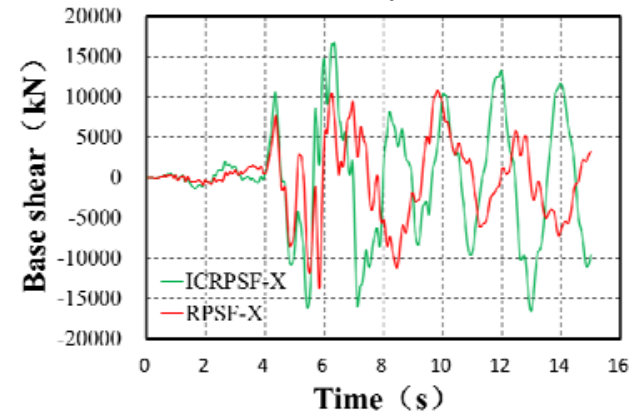

f) GM8 secondary direction

Figure 14. Base-shear Time-histories of Two Frames under 8.5-degree Rare Earthquake

The maximum base shears of both frames under 8.5-degree rare earthquake conditions both in primary and secondary directions are shown in Table 11. The data show that the ground motion with higher influence coefficient would exert a larger base shear on the structure. However, when compared with the response under rare earthquake ground motion, the corresponding increase is less significant. This indicates that, with the further increase of the earthquake magnitude and horizontal slippage of intermediate column, the contribution of ICFD to the overall rigidity of the structure decreases. 
Table 11. Maximum Base-shears of Two Frames under 8.5-degree Rare Earthquake

\begin{tabular}{ccccccc}
\hline $\begin{array}{c}\text { Ground } \\
\text { motions }\end{array}$ & \multicolumn{2}{c}{ Primary direction $(\mathrm{Z})$} & \multicolumn{3}{c}{ Secondary direction (X) } \\
& $\begin{array}{c}\text { RPSF } \\
\mathrm{kN}\end{array}$ & $\begin{array}{c}\text { ICRPSF } \\
\mathrm{kN}\end{array}$ & $\begin{array}{c}\text { Delta } \\
\%\end{array}$ & $\begin{array}{c}\text { RPSF } \\
\mathrm{kN}\end{array}$ & $\begin{array}{c}\text { ICRPSF } \\
\mathrm{kN}\end{array}$ & $\begin{array}{c}\text { Delta } \\
\%\end{array}$ \\
\hline GM1 & 20206 & 26591 & 32 & 16377 & 26677 & 63 \\
GM2 & 16474 & 17587 & 7 & 12414 & 20530 & 65 \\
GM3 & 18560 & 21651 & 17 & 14630 & 24384 & 67 \\
GM4 & 12451 & 16609 & 33 & 19327 & 21454 & 11 \\
GM5 & 17340 & 20824 & 20 & 13807 & 18827 & 36 \\
GM6 & 17884 & 12954 & -28 & 14090 & 16216 & 15 \\
GM7 & 14683 & 19502 & 33 & 13898 & 20648 & 49 \\
GM8 & 12126 & 15913 & 31 & 13725 & 16747 & 22 \\
\hline
\end{tabular}

(3) Comparison of the story drift

Figure 15 shows the envelope curves of the story drifts of each floor for both frames in the primary and secondary directions under different ground motions. The maximum story drifts are shown in Table 12. The data in Figure 15 and Table 12 show that, in the primary and the secondary directions, the maximum story drifts of the ICRPSF are smaller than those of the RPSF under most ground motions. The maximum story drift of RPSF is 3.223\% under GM3 ground motion, which is greater than the maximum story drift of $2.190 \%$ of ICRPSF under the same ground motion. The ICRPSF is superior to the RPSF on the control of the story drift.

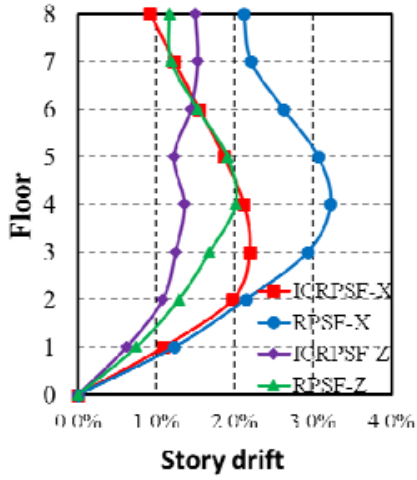

a) GM3

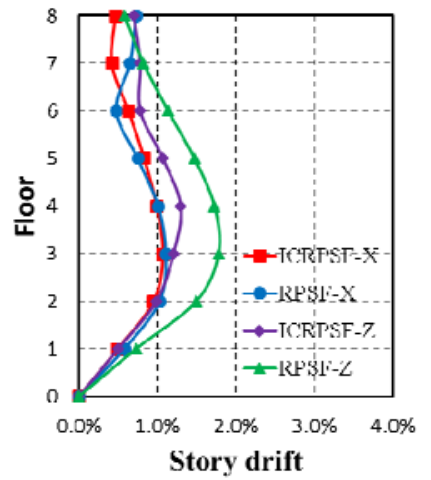

b) GM5

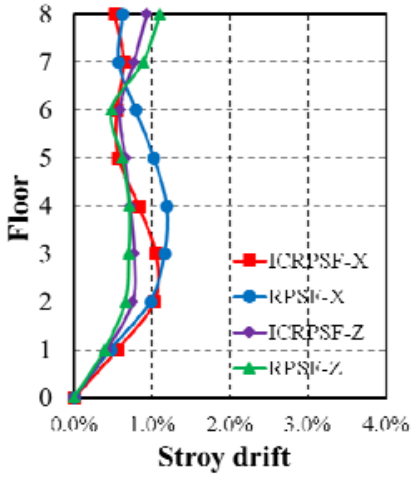

c) GM8

Figure 15. Comparison of Maximum Story Drift of Two Frames under 8.5-degree Rare Earthquake

Table 12. Maximum Story Drift of Two Frames under 8.5-degree Rare Earthquake（\%rad）

\begin{tabular}{ccccc}
\hline $\begin{array}{c}\text { Ground } \\
\text { motions }\end{array}$ & \multicolumn{2}{c}{ Primary direction (Z) } & \multicolumn{2}{c}{ Secondary direction (X) } \\
RPSF & ICRPSF & RPSF & ICRPSF \\
\hline GM1 & 1.625 & 2.014 & 2.206 & 2.197 \\
GM2 & 1.176 & 1.523 & 1.630 & 1.693 \\
GM3 & 2.012 & 1.527 & 3.223 & 2.190 \\
GM4 & 0.749 & 0.731 & 1.318 & 0.919 \\
GM5 & 1.779 & 1.298 & 1.108 & 1.071 \\
GM6 & 0.389 & 0.569 & 0.446 & 0.586 \\
GM7 & 1.651 & 1.568 & 1.452 & 1.090 \\
GM8 & 1.102 & 0.930 & 1.186 & 1.048 \\
\hline
\end{tabular}


(4) Comparison of the residual story drift

Figure 16 shows a comparison of the maximum residual story drifts between both frames of each floor under different 8.5-degree rare ground motions. The maximum residual story drift of the ICRPSF is smaller than that of the RPSF, i.e., they are $0.121 \%$ and $0.287 \%$, respectively. The former has superior post-seismic recovering capability.

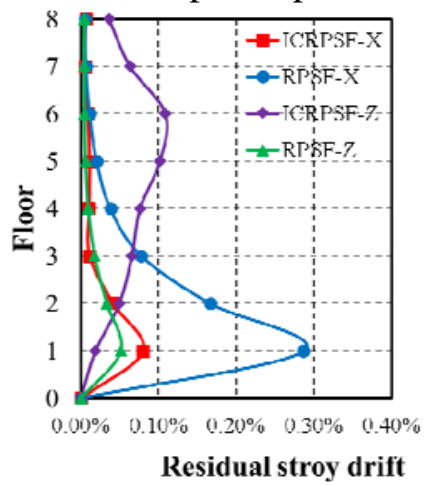

a) GM3

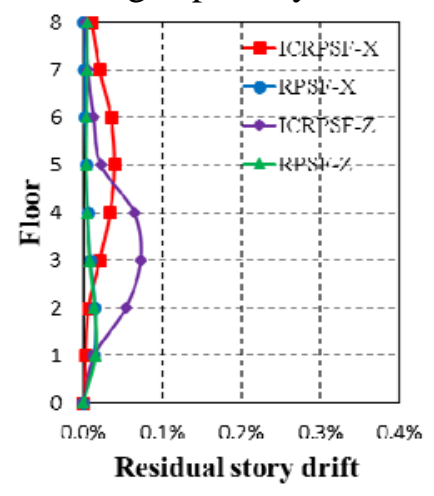

b) GM5

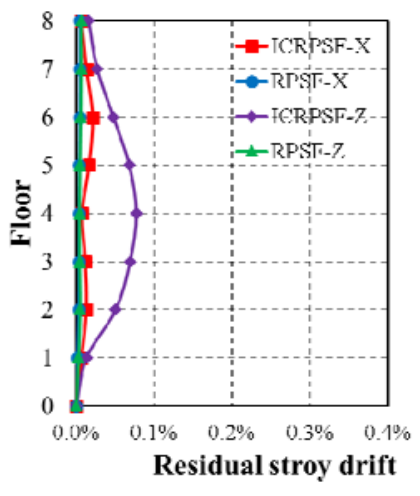

c) GM8

Figure 16. Maximum residual story drift of two frames under 8.5-degree rare earthquake

Table 13 shows the maximum residual slippages of the friction dampers of both frames under 8.5-degree rare earthquake conditions. After the friction damper experiences a larger slip, the corresponding residual slippage also increases. However, this will have significant influence on the overall performance of the structure. Additionally, after an earthquake, the high-strength bolt can be relaxed to restore the ICFD to its original position.

Table 13. Maximum ICFD Residual Slippage under 8.5-degree Rare Earthquake（ $\mathrm{mm} ）$

\begin{tabular}{|c|c|c|c|c|c|c|c|c|c|}
\hline \multicolumn{2}{|c|}{ Ground motions } & GM 1 & GM 2 & GM 3 & $\begin{array}{c}\text { GM } \\
4\end{array}$ & GM 5 & GM 6 & GM 7 & $\begin{array}{c}\mathrm{GM} \\
8\end{array}$ \\
\hline \multirow{2}{*}{ ICRPSF } & $\begin{array}{c}\mathrm{Z} \\
\text { direction }\end{array}$ & 14.4 & 3.1 & 0.4 & 15.2 & 2.2 & 4.0 & 4.0 & 9.8 \\
\hline & $\begin{array}{c}\mathrm{X} \\
\text { direction }\end{array}$ & 13.1 & 3.0 & 7.3 & 4.9 & 4.4 & 3.8 & 2.9 & 2.7 \\
\hline
\end{tabular}

(5) Comparison of frame plasticity and energy dissipation

Under 8.5-degree rare earthquake conditions, the PEEQ for the column bases and beams of both frames is shown in Table 14. The data in Table 14 show that the PEEQ in the column base of both frames increases slightly than that under 8-degree rare earthquake conditions. The frame beam still remains in an elastic state, and the column bottoms of both frames have the similar plastic developing conditions. 
Table 14. PEEQ of Two Frames under 8.5-degree Rare Earthquake

\begin{tabular}{|c|c|c|c|c|c|}
\hline \multirow{2}{*}{$\begin{array}{l}\text { Ground } \\
\text { motions }\end{array}$} & \multicolumn{2}{|c|}{ RPSF } & \multicolumn{3}{|c|}{ ICRPSF } \\
\hline & column base & beam & column base & intermediate column base & beam \\
\hline GM1 & $1.79 \times 10^{-3}$ & - & $2.73 \times 10^{-3}$ & $1.24 \times 10^{-3}$ & - \\
\hline GM2 & $2.39 \times 10^{-4}$ & 一 & $5.52 \times 10^{-4}$ & $3.22 \times 10^{-4}$ & - \\
\hline GM3 & $4.71 \times 10^{-3}$ & - & $4.95 \times 10^{-3}$ & $7.29 \times 10^{-4}$ & - \\
\hline GM4 & - & - & - & 一 & - \\
\hline GM5 & $3.81 \times 10^{-6}$ & - & - & $2.30 \times 10^{-7}$ & - \\
\hline GM6 & $5.82 \times 10^{-5}$ & - & $1.56 \times 10^{-5}$ & - & - \\
\hline GM7 & - & - & - & $9.59 \times 10^{-4}$ & - \\
\hline GM8 & - & - & $2.26 \times 10^{-4}$ & $2.17 \times 10^{-4}$ & - \\
\hline
\end{tabular}

*: -represent elastic

Figure 17 shows a comparison of the energy dissipation between the two frames. Table 15 shows the detailed energy dissipation values. Under different ground motions, the total energy absorbed by the ICRPSF structure is $44.4 \%$ greater than that by the RPSF on average, the maximum energy absorbed by the ICRPSF under GM2 is twice as that by the RPSF, indicating that the intermediate column contributes to the overall rigidity of the structure significantly. Under 8.5-degree rare earthquake conditions, the friction energy dissipation increases and the damping energy dissipation decreases. Under the three ground motions with larger influence coefficients, the friction energy dissipation takes up more than half of the total energy dissipation, which the maximum value reaches 55.12\%. The friction energy dissipation performance of the ICRPSF is superior to the RPSF significantly. The non-elastic energy dissipation of ICRPSF and RPSF has the relatively small proportion of the total energy dissipation under 8.5-degree rare earthquakes, which the average value of RPSF is $7.37 \%$ and to ICRPSF, is only 3.91\%. Therefore, the plastic development of the ICRPSF is less than that of the RPSF, which improves post-seismic recovery performance.

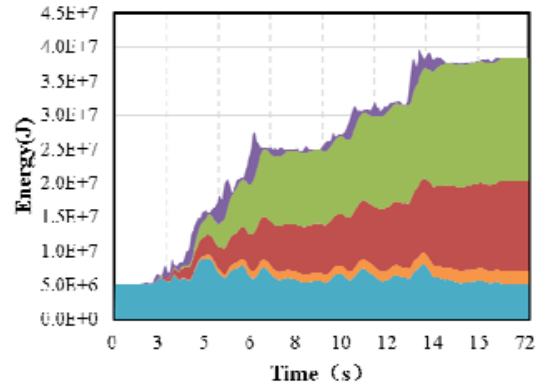

a) GM3 ICRPSF

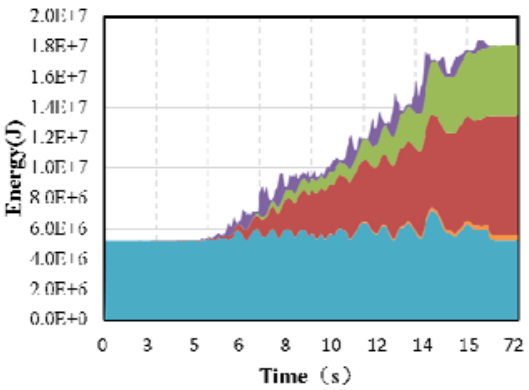

c) GM5 ICRPSF

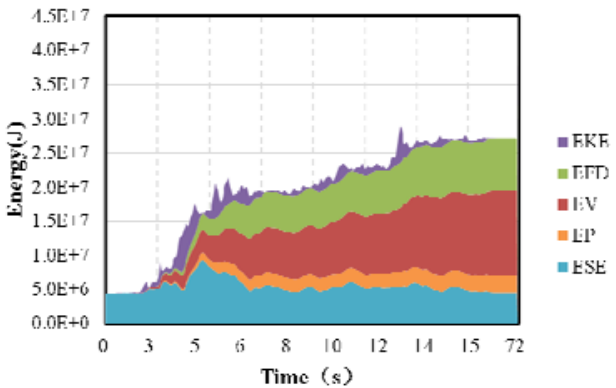

b) GM3 RPSF

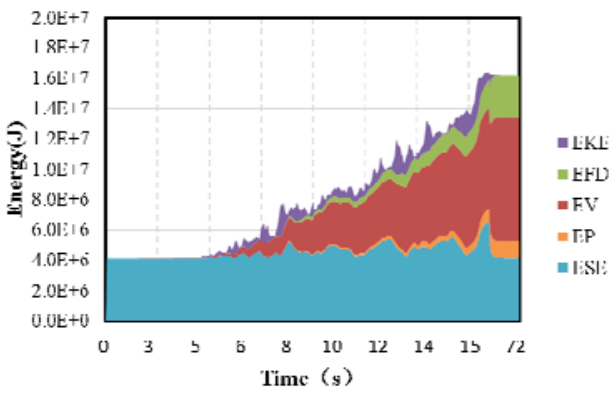

d) GM5 RPSF 


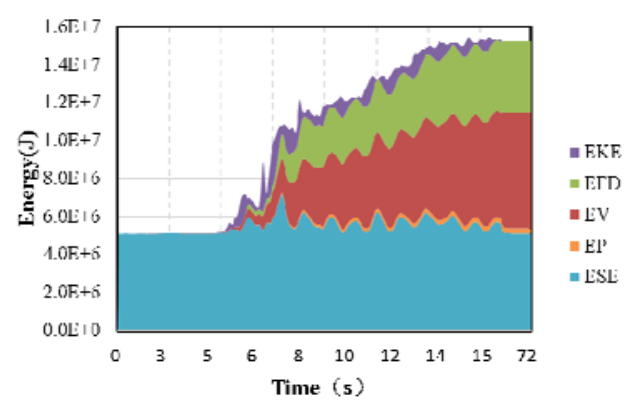

e) GM8 ICRPSF

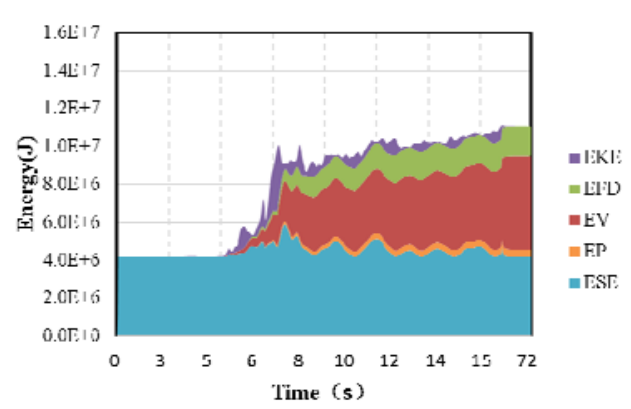

f) GM8 RPSF

Figure 17 Comparison of energy dissipation of two frames under 8.5-degree rare earthquake

Table 15. Energy Dissipation of Two Frames under 8.5-degree Rare Earthquake

\begin{tabular}{cccccccccc}
\hline Ground motions & WK(J) & ESE(J) & EKE(J) & EWK(J) & EP(J) & $\begin{array}{c}\text { EP/EWK } \\
(\%)\end{array}$ & $\begin{array}{c}\text { EV/EWK } \\
(\%)\end{array}$ & $\begin{array}{c}\text { EFD/EWK } \\
(\%)\end{array}$ \\
\hline \multirow{2}{*}{ GM1 1} & RPSF & 21276800 & 4275280 & 151868 & 16849652 & 1433040 & 8.50 & 54.40 & 36.78 \\
& ICRPSF & 31000800 & 5698340 & 111802 & 25190658 & 1618030 & 6.42 & 39.34 & 53.65 \\
GM2 & RPSF & 12875000 & 4182780 & 8610 & 8683610 & 437003 & 5.03 & 70.42 & 24.02 \\
& ICRPSF & 24426800 & 5256710 & 253515 & 18916575 & 686605 & 3.63 & 50.29 & 45.27 \\
GM3 & RPSF & 27270300 & 4679850 & 447171 & 22143279 & 2498360 & 11.28 & 53.81 & 34.58 \\
& ICRPSF & 38641100 & 5580590 & 502779 & 32557731 & 1839880 & 5.65 & 38.74 & 55.12 \\
GM4 & RPSF & 12176800 & 4453980 & 1422920 & 6299900 & 397867 & 6.32 & 78.40 & 14.62 \\
& ICRPSF & 15180200 & 5694810 & 1243090 & 8242300 & 233834 & 2.84 & 63.37 & 31.95 \\
GM5 & RPSF & 16454200 & 6536690 & 537917 & 9379593 & 846174 & 9.02 & 70.52 & 19.69 \\
& ICRPSF & 18341800 & 5957690 & 218524 & 12165586 & 297370 & 2.44 & 58.47 & 37.70 \\
GM6 & RPSF & 23329100 & 4589540 & 367320 & 18372240 & 916400 & 4.99 & 83.56 & 10.81 \\
& ICRPSF & 13866200 & 5287400 & 676589 & 7902211 & 60007 & 0.76 & 95.99 & 1.42 \\
GM7 & RPSF & 13012300 & 4251090 & 637004 & 8124206 & 654308 & 8.05 & 66.80 & 24.20 \\
& ICRPSF & 19606900 & 5485520 & 602023 & 13519357 & 832700 & 6.16 & 46.65 & 46.00 \\
GM8 & RPSF & 11028900 & 4298690 & 673499 & 6056711 & 350814 & 5.79 & 69.02 & 24.54 \\
& ICRPSF & 15450000 & 5646320 & 74586 & 9729094 & 274582 & 2.82 & 57.32 & 38.36 \\
\hline \multicolumn{5}{c}{$*$ total energy absorption: WK= ESE+ EKE+ EWK; total energy dissipation: EWK= EP+ EV+EFD }
\end{tabular}

\section{CONCLUSIONS}

(1) Compared with the RPSF frame, the ICRPSF has a shorter period. The difference between the two frames is $26 \%$ approximately. The existence of the ICFD results in a significant increase of the lateral rigidity and torsional rigidity of ICRPSF compared with the RPSF. The intermediate column contributes to the overall translational and rotational rigidity of the structure significantly.

(2) Additional rigidity provided by the ICFD causes the greater maximum base shear of the ICRPSF than that of the RPSF under most conditions. Slip occurs at the ICFD with the increase of earthquake magnitude, decreasing the difference between the lateral rigidities of the two frames, and resulting in approximate base shears of the two frames.

(3) The lateral rigidity of ICRPSF is higher than that of RPSF. Under various earthquake conditions, the maximum story drifts of ICRPSF are all smaller than those of RPSF. Under the action of 8.5-degree rare earthquakes, the maximum story drift of RPSF is $3.22 \%$, which is far 
beyond the elasto-plastic story drift limit of $2 \%$ in current code. The corresponding story drift of ICRPSF is only $2.19 \%$ (1/46), which just exceeds the code limit. These results show that ICRPSF has a significantly superior performance on the control of the story drift than RPSF.

(4) Both frames have very small post-seismic residual story drift under design earthquakes, which can be ignored. The maximum residual story drifts of ICRPSF under 8.5-degree rare earthquake conditions are all smaller than those of the RPSF, and the maximum residual deformation of the structure is $0.121 \%$. However, the larger ICFD slip results in the larger residual slippage correspondingly. This will have a few influences on the overall performance of the structure. However, after an earthquake, the high strength bolt can be relaxed to restore the ICFD to its original position.

(5) When the earthquake magnitude is relatively small, the energy absorbed by the frames is elastic strain energy primarily. With the increase of the earthquake magnitude, the damping energy dissipation and friction energy dissipation increasing gradually, while the increase in the non-elastic energy dissipation is relatively small in either of the frame. The total absorbed energy and friction energy dissipation in the ICRPSF are always greater than those of the RPSF, while its non-elastic energy dissipation is always less than that of the RPSF. Under the earthquake conditions of high earthquake magnitudes, the friction energy dissipation of the ICRPSF represents almost half of the total energy dissipation, and ICFD contributes to the overall seismic energy dissipation of the structure significantly.

(6) In conclusion, the resilient prestressed steel frame with intermediate column containing friction dampers can effectively control the story drift and dissipate more energy, slow down the plastic development of the components even further, and achieve small post-seismic structure residual story drift. Such superior performance will be more evident with the increase of the earthquake magnitudes. Therefore, this system is very suitable for the resilient prestressed steel frame structure with a large span, the structure which locates in the frequent earthquake zone and a high-value building.

\section{ACKNOWLEDGEMENT}

This work was supported by the National Key Basic Research and Development Program of China under Grant No.2016YFC0701504 and the Key Project of Beijing Natural Science Foundation under Grant No.8131002.

\section{REFERENCES}

[1] Ricles, J.M., Sause, R., Garlock, M. and Zhao, C., "Post-tensioned Seismic-resistant Connections for Steel Frames,” Journal of Structure Engineering, 2001, Vol. 127, No. 2. pp.113-121.

[2] Garlock, M., Ricles, J. M. and Sause, R. "Cyclic Load Tests and Analysis of Bolted Top-and-seat Angle Connections,” Journal of Structure Engineering, 2003, Vol. 129, No. 12, pp.1615-1625.

[3] Garlock, M., Sause, R. and Ricles, J. "Behavior and Design of Posttensioned Steel Frame Systems,” Struct. Eng, 2007, Vol. 133, No. 3, pp.389 - 399.

[4] Christopoulos, C., Filiatrault, A., Uang, C. M., and Folz, B. "Post-tensioned Energy Dissipating Connections for Moment-resisting Steel Frames,” Journal of Structural Engineering, 2002, Vol. 128, No. 9, pp. 1111-1120. 
[5] Rojas, P., Ricles, J. M. and Sause, R. "Seismic Performance of Post-tensioned Steel Moment Resisting Frames with Friction Devices,” Journal of Structural Engineering, 2005, Vol. 131, No. 4, pp. 529 - 540.

[6] Wolski, M., Ricles, J. M. and Sause, R., "Experimental Study of a Self-centering Beam-column Connection with Bottom Flange Friction Device," Journal of Structure Engineering, 2009, Vol. 135, No. 5, pp. 479-488.

[7] Tsai, K. C., Chou, C. C., Lin, C. L., Chen, P. C. and Jhang, S. J., "Seismic Self-centering Steel Beam-to- column Moment Connections using Bolted Friction Devices, ”Earthquake Engineering and Structural Dynamics, 2008, Vol. 37, pp. 627-645.

[8] Lin, Y.C., Sause, R. and Ricles, J.M., "Seismic Performance of Steel Self-centering, Moment-resisting Frame: Hybrid Simulations under Design Basis Earthquake”, Journal of Structural Engineering, 2013, Vol. 139, No. 5, pp. 1823-1832.

[9] Lin, Y. C., Sause, R. and Ricles, J. M., "Seismic Performance of a Large-scale Steel Self-centering Moment-resisting Frame: MCE Hybrid Simulations and Quasi-static Pushover Tests”, Journal of Structural Engineering, 2013, Vol. 139, No. 7, pp.1227-1236.

[10] Zhang, Y. X., Zhang, A. L. and Sun, W.L., "Behavior Study of Self-centering Beam-column Connections in Resilient Steel Frames after Earthquake”, Industrial Construction, 2014, Vol. 44, No. 502, pp. 160-167. (in Chinese)

[11] Zhang, Y. X., Ye, J. J., Yang, F. and Chen, Y. Y., "Dynamic Behavior and Time-history Analysis of Integral Self-centering Moment Resisting Frames”, China Civil Engineering Journal, 2015, Vol. 48, No. 7, pp. 30-40 (in Chinese)

[12] Zhang, A. L., Zhang, Y. X., Li, R. and Wang, Z. Y., "Cyclic Behavior of a Prefabricated Self-centering Beam-column Connection with a Bolted Web Friction Device”, Engineering Structures, 2016, Vol. 111, pp. 185-198

[13] Zhang, A. L., Zhang, Y. X., Zhao, W. and F, C. C., "Pseudo Dynamic Test Study of Resilient Prefabricated Prestressed Steel Frame”, Journal of Vibration and Shock, 2016, Vol. 35, No. 05, pp. 207-215 (in Chinese)

[14] Zhang, A. L., Zhang, Y. X., Cheng, Y. Y. and Wang, Z.Y., "Static Pushover Test on Resilient Prestressed Steel Frame with Intermediate Column Containing Friction Dampers”, Journal of Building Structures, 2016, Vol. 03, pp. 125-133 (in Chinese)

[15] Japan Association of Vibration Isolation Structure, "Passive Suspension Structure Design and Construction Manuals,” Architecture \& Building Press, Beijing, China, 2008. (in Chinese)

[16] ATC-63. "Quantification of Building Seismic Performance Factors,” Applied Technology Council, 2008.

[17] GB 50011-2010, “Code for Seismic Design of Buildings,” Architecture \& Building Press, Beijing, China, 2010. (in Chinese) 